\title{
Integrating assortment selection, pricing and mixed-bundling problems for multiple retail categories under cross-selling
}

\author{
Masoud Rabbani ${ }^{a^{*}}$, Razieh Salehi ${ }^{\mathrm{b}}$ and Amir Farshbaf-Geranmayeh ${ }^{\mathrm{c}}$
}

\author{
${ }^{a}$ Professor, School of Industrial Engineering, College of Engineering, University of Tehran, Tehran, Iran \\ ${ }^{b}$ M.Sc student, School of Industrial Engineering, College of Engineering, University of Tehran, Tehran, Iran \\ ${ }^{c}$ Ph.D. candidate, School of Industrial Engineering, College of Engineering, University of Tehran, Tehran, Iran

\section{H R O N I C L E}

\section{A B S T R A C T}

Article history:

Received December 2, 2016

Received in revised format

December 10, 2016

Accepted April 202017

Available online

May 32017

Keywords:

Cross-selling

Assortment selection

Mixed bundling

Pricing

Mixed-integer programming
This paper optimizes joint mixed bundling, assortment planning and pricing problems for complementary retail categories that comprise substitutable items. These categories are divided into one primary category and multiple secondary categories and based on cross-selling effect, customers of primary category can opt to buy from other categories. It is assumed that the bundle can comprise one product of each offered complementary categories. A mixed-integer nonlinear programming is proposed that maximizes total profit by optimizing strategy of bundling, assortment selection and prices of single products and the bundle under a maximumsurplus customer choice model. Then because of computational considerations, this model is linearized and converted to a mixed-integer linear programming; whereby exact solution for even large-scale problems can be obtained. The results show that if cross-selling effect between product categories is overlooked or bundling of products is not allowed, then significant profit losses, will be resulted. To the best of our knowledge, this is the first study on bundling strategies in assortment selection decisions.

\section{Introduction}

The assortment planning problem is to specify an assortment-the set of products carried in the store, which maximizes profit subject to various constraints. This problem is derived from product line design problem where a subset of products and their prices are selected and they are sold to multiple segments of customers with different behaviors in order to maximize total profit. Because certain retail categories are interdependent, ignoring the effect of cross-selling on optimizing assortment planning of complementary categories may result in sub-optimal assortments (Ghoniem et al., 2013). Based on an asymmetric cross-selling effect that is often observed, demand of the "secondary" complementary categories can be derived from one "primary" category's demand (Walters, 1991). In this study, such asymmetric cross-selling effect is considered and customers' demand for the secondary categories can be considered as a direct demand or be derived from primary category's demand by cross-selling effect.

* Corresponding author Fax: +982188013102

E-mail address: mrabani@ut.ac.ir (M. Rabbani)

C 2017 Growing Science Ltd. All rights reserved. doi: 10.5267/j.uscm.2017.5.001 
In other hand, many customers may pay attention to sell a package of products instead of selling products individually. In the literature, bundling is referred to the strategies of selling products in two followed ways: only in package form (i.e. pure bundling), or in packages as well as separately (i.e. mixed bundling). Also unbundling (i.e. pure components) is referred to the case that all products only can be sold individually. Whereas the application of bundling is used as an efficient method in many different industry sectors, and can sort customers into groups with different reservation prices and help to extracting customer surplus (Adams \& Yellen, 1976). To the best of authors' knowledge there is no study that considers bundling strategy in assortment planning decisions. Obviously, when bundling and assortment planning decisions are considered as an integrated decision; the obtained total profit can be improved relative to when these decisions are made separately in two distinct steps. In this study, a mixed bundling strategy is involved in assortment planning decisions where the bundles can comprise one product of each offered complementary categories.

This study presents a mathematical programming that under cross-selling effects and maximum-surplus customer choice model optimizes the prices and assortment selection of multiple retail categories, as well as bundling strategy of complementary products. In fact, this model simultaneously determines the optimum individual products and bundles that should be offered in a retail store as well as their optimum prices. For this purpose a mixed-integer nonlinear programing is proposed. Then because of computational considerations, this model is linearized and the obtained mixed-integer linear programing is solved applying CPLEX solver and an exact solution is obtained for even large-scale instances. Because of tractability of the proposed model and obtaining exact solution there is not any requirement for applying heuristic and/or meta-heuristic methods. This study, for the first time, proposes joint optimization of pricing, bundling and assortment planning decisions for multiple product categories and presents an exact solution for this problem.

The structure of this study is organized as follows: Section 2 presents the related literature review. Problem description and model formulation are presented in section 3, in section 4 a computational study is examined and sensitivity analysis is presented in section 5. Finally section 6 concludes the paper and discusses our findings, as well as directions for future research.

\section{Literature review}

This paper involves two aspects of literature including assortment planning and bundling. The first aspect is related to the literature on retail category optimization; and the last considers bundling a given assortment of products. Present work brings the concept of bundling into assortment planning decisions with multiple categories. In the remainder of this section these two aspects of literature are discussed.

\subsection{Literature of assortment planning}

The history of assortment planning returns to product line design problem pioneered by Mussa and Rosen (1978) and Moorthy (1984). With growing interest in basket shopping, many researchers focus on category management. For example Cachon and Kök (2007) in the presence of basket-shopping customers and multiple product categories; studied the pricing and assortment planning under category management. Chena and Jianga (2016) presented a mathematical model to find maximum revenue based on optimal set of products and their prices under capacity constraint.

In the research of assortment planning problem it is necessary to adopt a choice model that adequately describes the behavior of customers. In most cases, customer choice model is represented by the maximum-surplus choice rule, which surplus is defined as customer reservation price (maximum price that the customer is willing to pay for the product) minus actual price of product set by the seller. This choice rule is usually used for cases that from the customers' perspective the surplus is a determinant factor for purchasing. Johnson (1974) for applications that customers have a high degree of sensitivity to the surplus; supported the assumption of customer choice model based on maximum-surplus rule. 
Rodríguez and Aydin (2011) considered the importance of variant's surplus; for a firm selling a configurable product including a required component and several optional components. They determined the optimal price and variant of components based on maximum-surplus rule for customer choice. In their study, a customer first buys a required product and then under a cross-selling effect considers buying an optional product. Ghoniem et al. (2013) optimized the assortment and pricing decisions for complementary retail categories assuming customers' choice behavior as maximumsurplus model and exerting cross-selling considerations. Katsifou et al. (2014) introduced a combined assortment including standard and special products, to increase store traffic; and analyze inventory level, pricing, and product assortment under cross selling effect. They proposed that with decreasing cross-selling, a retailer should increase the size of standard assortment and decrease the prices. Also they suggested that ignoring cross-selling effect may decrease the profit of retailer. There are many other studies that have considered inventory decisions in assortment planning or pricing problem (e.g. Surti et al., 2013; Bhunia \& Shaikh, 2014). For example, Zhang (2012) determined optimum price, promotion, and ordering quantity to maximize total profit. Jaggi et al. (2015) developed an inventory model for deteriorating items under inflationary conditions to optimize pricing and inventory decisions, to maximize the profit.

However, for some applications that surplus is not important for customers; logit or probabilistic choice models may be appropriate. For example, Kraus and Yano (2003) considered a probabilistic choice model based on share-of-surplus model and Maddah and Bish (2007) used a multinomial logit choice model for customer choice process. Also in the literature, assortment planning problem may be considered dynamically for a multi-period horizon (e.g., Hall et al., 2010; Talebian et al., 2014, Rabbani et al., 2014) or applied in an oligopolistic environment instead of a monopolistic one (e.g. Draganska et al., 2009; Zhang, 2015); also, the price may be changed over planning horizon (Saha \& Basu, 2010). As Ghoniem et al. (2013) mentioned, there are many significant computational challenges in the literature of product line optimization problems, and this problem have been mostly tackled via heuristics (McElreath et al., 2010). Ghoniem et al. (2013) for optimizing joint pricing and assortment planning decisions presented an exact solution to large problem instances.

\subsection{Literature of bundling}

Over the past decades, the study of offering two or more products or services as a bundle in order to achieve a company's maximum profit has attracted much attention. In a seminal work Adams, and Yellen (1976) examined the reason of using bundling as a prevalent strategy and express that bundling strategy has the ability to sort customers into groups with different reservation prices which can help to extracting customer surplus. Venkatesh and Kamakura (2003) focused on the practice of bundling substitutable or complementary products; and under a monopolistic environment studied the difference between joint pricing and bundling strategy of such products and interdependently valued products. Chew et al. (2014) examined the strategy of mixed bundling of two products under a stochastic and monopolistic market. They considered joint pricing and inventory decisions to maximize expected profit. Mayer et al. (2013) in order to analyze a mixed bundling problem, proposed two mixed-integer linear programs based on maximum-surplus model for customer choice behavior to determine optimum prices and bundling strategies. In their study, a monopolistic provider can select optimum prices from a set of discrete price points. Arora (2011) used a mixed qualitative and quantitative approach to explore the effectiveness of price bundling. Also there are many studies that examine bundling problem in a duopolistic or oligopolistic market (e.g., Liao \& Tauman, 2002). Cataldo and Ferrer (2016) developed a two-step approach to determine the optimal price and composition of the bundles when the price and characters of competitors' bundles are known. Meyer and Shankar (2016) presented an analytical model to optimize the price of hybrid service bundles by a monopolist retailer. In all above mentioned studies the bundling strategy is determined for a given assortment, although decision making about assortment planning and bundling in two distinct steps cannot ensure the best solution for maximization of profit. The joint optimization of bundling strategy and assortment planning was only studied by Azadeh et al. 
(2014) that considered deterministic bundling of two products. They solved the mentioned problem using integer nonlinear programming by LINGO software but because the results were not global, they also applied a Genetic Algorithm.

To the best of our knowledge, in this study for the first time joint optimization of pricing, bundling and assortment planning decisions for multiple product categories is considered and an exact solution is presented. The proposed model considers multiple customer segments and assumes the customer choice model based on maximum-surplus rule. The bundling strategy that examines in this model is a mixed bundling strategy for a monopolistic provider (retailer).

\section{Problem description and model formulation}

This study tries to maximize total profit of a retail store by determining optimum selection of assortments and bundle of single products, as well as prices of them. In this model $L$ complementary categories of retail products are considered that are divided into one primary category-first categoryand multiple secondary categories. All of these categories comprise substitutable items and each customer can only buy one of these substitutable products. A mixed bundling approach is possible that in which the bundles can comprise one product of each offered complementary categories. Based on cross-selling effect, customers of primary category may opt to buy from the secondary categories. The customers are from multiple segments that cross-selling effect on each segment is different; also each segment has its own reservation price. The behavior model of customers for selecting items is based on maximum-surplus rule; also items with negative surplus are not selected by any of the customer segments.

\subsection{Model formulation}

Based on the discussed assumptions, a mixed integer nonlinear programming formulation is summarized as follows:

\section{Indices}

L: $\quad$ Set of product categories

$N^{l}: \quad$ Set of customer segments for category $l$

$N^{b}$ : $\quad$ Set of customer segments for the bundle

$N_{l}: \quad$ Set of substitutable items in category $l$

\section{Parameters}

$s_{i}^{l}$ : The relative size of customer segment $i$ (the ratio of number of customer segment $i$ to total number of customers) for category $l$ by direct selling

$s_{i}^{b}$ : The relative size of customer segment $i$ for bundle by direct selling

$e_{i}{ }_{i}$ : Fraction of customer segment $i$ of the primary category who considers purchasing from products of secondary categories $k$

$e_{i}{ }_{i}$ : $\quad$ Fraction of customer segment $i$ of the primary category who considers purchasing the bundle

$g_{i j}^{l}$ : Reservation price of customer segment $i$ for product $j$ of category $l$

$h_{i j}{ }^{k}$ : Reservation price of customer segment $i$ of the primary category for a product $j$ in a secondary category $k$

$c_{j}^{l}$ : $\quad$ Unit ordering cost for product $j$ in category $l$

$f_{j}^{l}$ : $\quad$ Fixed cost for product $j$ in category $l$

$f_{b}$ : $\quad$ Fixed cost for bundle

$M$ : A large number 


\section{Decision Variables}

$z_{j}^{l} \quad 1$ if product $j$ from category $l$ is offered; 0 otherwise

$z b \quad 1$ if the bundle is offered; 0 otherwise

$b_{j}^{l} \quad 1$ if product $j$ from category $l$ is offered in the bundle; 0 otherwise

$x_{i j}{ }^{l} \quad 1$ if customer segment $i$ purchases product $j$ of category $l ; 0$ otherwise

$x_{i}^{b} \quad 1$ if customer segment $i$ purchases the bundle; 0 otherwise

$y_{i}^{b} \quad 1$ if customer segment $i$ purchases the bundle by cross-selling; 0 otherwise

$y_{i j}{ }^{k} \quad 1$ if customer segment $i$ purchases product $j$ in a secondary category $k$ by cross-selling; 0 otherwise

$p_{j}^{l}$ : $\quad$ Price of product $j$ in category $l$

$p_{b}: \quad$ Price of the bundle

$d_{j}{ }_{j}$ : $\quad$ Demand for product $j$ in category $l$

$d_{b}$ : Demand for bundle

$d_{j}^{l}$ and $d_{b}$ are endogenously calculated as a function of purchase decisions and the relative size of customer segments. The unit ordering cost for each bundle is equal to summation of unit ordering costs for its components, also similar to most bundling articles (Adams \& Yellen, 1976) it is assumed that reservation price of the bundle is equal to summation of reservation prices of component products.

This problem can be stated as the following mixed-integer nonlinear program. The objective function (1) maximizes the retailer's profit, that is, the difference between the retailer's revenue and variable costs for ordering products and fixed costs for including products in the assortment and in the bundle.

$$
\max w=\sum_{l \in L} \sum_{j \in N_{l}}\left(d_{j}^{l} p_{j}^{l}-c_{j}^{l} d_{j}^{l}-f_{j}^{l} \mathrm{z}_{j}^{l}\right)+d_{b} p_{b}-c_{b} d_{b}-f_{b} z_{b}
$$

S.t

$$
\begin{array}{ll}
d_{j}{ }^{1}=\sum_{i \in N^{1}} s_{i}{ }^{1} x_{i j}{ }^{1} & \forall j \in N_{1} \\
d_{j}{ }^{k}=\sum_{i \in N^{k}} s_{i}{ }^{k} x_{i j}{ }^{k}+\sum_{i \in N^{1}}\left(e_{i}{ }^{k} \mathrm{~s}_{i}{ }^{1}\right) \mathrm{y}_{i j}{ }^{k} & \forall k \in L \backslash 1 ; j \in N_{k} \\
d_{b}=\sum_{i \in N^{b}} s_{i}{ }^{b} \mathrm{x}_{i}{ }^{b}+\sum_{i \in N^{1}}\left(e_{i}^{b} \mathrm{~s}_{i}{ }^{1}\right) \mathrm{y}_{i}{ }^{b} & \\
p_{b} \leq \sum_{l \in L} \sum_{j \in N_{l}} p_{j}{ }^{l} b_{j}{ }^{l} & \\
\sum_{r \in N_{l}} b_{r}{ }^{l} \leq z_{j}{ }^{l} & \forall l \in L ; j \in N_{l} \\
\sum_{j \in N_{k}} y_{i j}{ }^{k} \leq M e_{i}{ }^{k} & \forall k \in L \backslash 1 ; i \in N^{k} \\
y_{i}^{b} \leq M e_{i}{ }^{b} & \forall i \in N^{b} \\
x_{i j}{ }^{l} \leq z_{j}{ }^{l} & \forall i \in N^{l} ; l \in L ; j \in N_{l} \\
y_{i j}{ }^{k} \leq z_{j}{ }^{k} & \forall i \in N^{k} ; \mathrm{k} \in L \backslash 1 ; j \in N_{k} \\
\sum_{r \in N_{l}}\left(\left(g_{i r}{ }^{l}-p_{r}{ }^{l}\right) \mathrm{x}_{i r}{ }^{l}\right) \geq\left(g_{i j}{ }^{l}-p_{j}{ }^{l}\right) \mathrm{z}_{j}{ }^{l} & \forall i \in N^{l} ; l \in L ; j \in N_{l}
\end{array}
$$




$$
\begin{aligned}
& \sum_{l \in L} \sum_{j \in N_{l}}\left(g_{i j}{ }^{l} b_{j}^{l} \mathrm{x}_{i}^{b}\right)-p_{b} \mathrm{x}_{i}^{b} \geq \sum_{l \in L} \sum_{j \in N_{l}}\left(g_{i j}{ }^{l}-p_{j}^{l}\right) b_{j}^{l} \quad \forall i \in N^{b} \\
& \sum_{j=N_{l}}\left(\left(g_{i j}{ }^{l}-p_{j}{ }^{l}\right) \mathrm{x}_{i j}{ }^{l}\right) \geq 0 \quad \forall i \in N^{l} ; l \in L \\
& \sum_{l \in L} \sum_{j \in N_{l}}\left(g_{i j}{ }^{l} b_{j}^{l} \mathrm{x}_{i}^{b}\right)-p_{b} \mathrm{x}_{i}^{b} \geq 0 \quad \forall i \in N^{b} \\
& \sum_{r \in N_{k}}\left(h_{i r}{ }^{k}-p_{r}{ }^{k}\right) \mathrm{y}_{i r}{ }^{k} \geq\left(h_{i j}{ }^{k}-p_{j}{ }^{k}\right) \mathrm{z}_{j}{ }^{k}-M\left(1-\sum_{i \in N^{1}} x_{i j}{ }^{1}\right) \quad \forall i \in N^{k} ; k \in L \backslash 1 ; j \in N_{k} \\
& \sum_{k \in L \backslash 1} \sum_{j \in N_{l}}\left(h_{i j}{ }^{k} b_{j}{ }^{k} y_{i}^{b}\right)-p_{b} y_{i}^{b} \geq \sum_{k \in L I} \sum_{j \in N_{l}}\left(h_{i j}{ }^{k}-p_{j}{ }^{k}\right) b_{j}{ }^{k}-M\left(1-\sum_{j \in N_{l}} \sum_{i \in N^{1}} x_{i j}{ }^{1}\right) \quad \forall i \in N^{b} \\
& \sum_{j \in N_{k}}\left(h_{i j}{ }^{k}-p_{j}{ }^{k}\right) \mathrm{y}_{i j}{ }^{k} \geq 0 \\
& \forall i \in N^{l} ; k \in L \backslash 1 \\
& \sum_{k \in L \backslash 1} \sum_{j \in N_{k}}\left(h_{i j}{ }^{k} b_{j}^{k} y_{i}^{b}\right)-p_{b} y_{i}^{b} \geq 0 \\
& \forall i \in N^{b} \\
& x_{i}^{b} \leq z_{b} \\
& \forall i \in N^{b} \\
& y_{i}^{b} \leq z_{b} \\
& \forall i \in N^{b} \\
& \sum_{j \in N_{l}}\left(x_{i j}{ }^{l}+b_{j}{ }^{l} x_{i}^{b}\right) \leq 1 \\
& \forall i \in\left\{N^{l} \cup N^{b}\right\} ; l \in L \\
& \sum_{j \in N_{l}}\left(y_{i j}{ }^{l}+b_{j}{ }^{l} y_{i}^{b}\right) \leq \sum_{j \in N_{l}}\left(x_{i j}{ }^{1}+b_{j}{ }^{l} x_{i}^{b}\right) \\
& \forall i \in\left\{N^{l} \cup N^{b}\right\} ; l \in L \\
& p_{j}{ }^{k} \leq M \sum_{i \in N^{k}}\left(x_{i j}{ }^{k}+y_{i j}{ }^{k}\right) \\
& \forall k \in L \backslash 1 ; j \in N_{k} \\
& p_{j}{ }^{1} \leq M \sum_{i \in N^{1}} x_{i j}{ }^{1} \\
& \forall j \in N_{1} \\
& x_{i j}^{l}, x_{i}^{b}, z_{b}, z_{j}^{l}, y_{i j}{ }^{k}, y_{i}^{b}, b_{j}^{l} \in\{0,1\} \\
& \forall i \in N^{l} ; j \in N_{l} ; l \in L \\
& p_{b}, p_{j}^{l}, d_{b}, d_{j}^{l} \geq 0 \\
& \forall j \in N_{l} ; l \in L
\end{aligned}
$$

Constraints (2), (3) and (4) determine demand for primary category, secondary categories and bundle, respectively. Based on this constraints demand for bundle and secondary categories are obtained from both direct selling and cross-selling; whereas demand of primary category is only related to direct selling. Constraints (5) assign a discounted price to the bundle. Constraints (6) ensure that only presented products can be placed in a bundle. According to constraints (7) and (8) when the effect of cross-selling is ignored, the value of variable $y$ is set to zero. Constraints (9) and (10) ensure that customers only can purchase offered products. Based on Constraints (11) each customer segment purchases the products that have maximum surplus among other substitutable items. Whereas constraints (12) ensure that a purchased bundle has a greater surplus than each set of single products that can constitute this bundle; in other word, based on these constraints, between all sets of products that can constitute a bundle, an alternative should be selected that provide maximum bundle surplus. Constraints (13) and (14) prevent from negative surplus. While last four constraints are defined for direct selling, constraints (15), (16), (17) and (18) do same practices for cross-selling. The terms contains $M$ in constraints (15) and (16) indicate that these constraints only when need to be satisfied that at least one product from primary category is purchased. In these constraints $M$ is an adequately 
great number. According to constraints (19) and (20) customers can purchase a bundle by direct or cross-selling only if the bundle has been offered. Based on constraints (21) each customer segment only can purchase one item between substitutable items, also each product can purchased only individually or in bundle. Constraints (22) exert this for cross considering that cross-selling only can occurred for customers that purchase from primary category. Constraints (23) and (24) ensure that only the price of purchased products is required to determine. Finally, constraints (25) and (26) enforce the binary and non-negativity restrictions on corresponding decision variables.

\subsection{Linearizing the model}

As seen from the model, objective function and some constraints include terms as $p_{j}{ }_{j} b_{j}{ }^{l} ; p_{j}{ }^{l} x_{i j}{ }^{l}$; $p_{j}{ }^{k} y_{i j}{ }^{k} ; p_{b} x_{i}^{b} ; p_{j}{ }^{1} y_{i}^{b}$ and $p_{j}{ }^{l} z_{j}^{l}$. Because of computational considerations and to enable model to run for larger data sets, we linearize the model by converting these terms to linear terms. For example $p_{j}^{l} b_{j}^{l}$ can linearize as follows:

$$
\begin{array}{ll}
p b_{j}^{l} \geq p_{j}^{l}-M b_{j}^{l} & \forall l \in L ; j \in N_{l} \\
p b_{j}^{l} \leq p_{j}^{l} & \forall l \in L ; j \in N_{l} \\
p b_{j}^{l} \leq M b_{j}^{l} & \forall l \in L ; j \in N_{l}
\end{array}
$$

All products of each two variables in Eq. (1) can be linearized as above; that for summarization, expression of them is regarded. The Eq. (1) should be reformulated by replacing product of each two variables using variables of $p b_{j}^{l}$. For example reformulated objective function is as follows:

$$
\max w=\sum_{i \in N^{l}} \sum_{l \in L} \sum_{j \in N_{l}} s_{i}^{l} p x_{i j}^{l}+\sum_{i \in N^{l}} \sum_{k \in L \backslash} \sum_{j \in N_{l}} e_{i}^{k} s_{i}^{1} p y_{i j}^{k}+\sum_{i \in N^{N^{l}}} s_{i}^{b} p x_{i}^{b}+\sum_{i \in N^{l}} e_{i}^{b} s_{i}^{1} p y_{i}^{b}-\sum_{l \in L} \sum_{j \in N_{l}}\left(c_{j}^{l} d_{j}^{l}+f_{j}^{l} z_{j}^{l}\right)-\left(d_{b} c_{b}+f_{b} z_{b}\right)
$$

where

$$
\begin{array}{ll}
p x_{i j}{ }^{l}=p_{j}{ }^{l} x_{i j}{ }^{l} & p y_{i j}{ }^{k}=p_{j}{ }^{k} y_{i j}{ }^{k} \\
p x_{i}^{b}=p_{b} x_{i}^{b} & p y_{i}{ }^{k}=p_{b} y_{i}{ }^{b}
\end{array}
$$

Also we have

$$
\begin{array}{ll}
p z_{j}{ }^{l}=p_{j}{ }^{l} z_{j}{ }^{l} & b x_{i j}{ }^{l}=b_{j}{ }^{l} x_{i}^{b} \\
b y_{i j}{ }^{k} & =b_{j}{ }^{k} y_{i}{ }^{b}
\end{array}
$$

By replacing each above variables in the objective function and nonlinear constraints; the mixed-integer linear programming (30) with 49 constraints is obtained that can be solved by CPLEX and exact solutions can be obtained even for large-scale problems.

\section{Results and discussions}

To illustrate validity of the proposed model, in this section a numerical example is presented that considers three product categories for two customer segments. Data for this example is shown in Table 1.Then this model is applied for larger instances that are scaled with respect to the number of categories, the number of candidate products in each category, and the number of customer segments for each category. All runs have been performed with GAMS 22.9/CPLEX solver on Microsoft Windows 7 
Ultimate with an Intel Core i5-4210U, 2.40GHz processor and 6GB RAM. This model is solved also without considering the effect of cross-selling and bundling possibility and the results are compared. For this end, the effect of cross-selling is ignored by setting $e_{j}^{l}$ and $e_{b}$ values to zero for all $i, j, l$; also by adding a new constraints $b_{j}{ }^{l}=0$ to the model for all $j, l$, constituting the bundle is not allowed. Table 2 shows the solution of this example. Consider that in Table 2 when a bundle is purchased the variable $b$ is shown by 1 and the state "in bundle" has been shown for the products that constitutes the bundle. In this table $j$ th product of $l$ th category has been indicated by $(j, l)$.

Table 1

Data for the example with two secondary categories

\begin{tabular}{|c|c|c|c|c|c|c|c|c|c|c|}
\hline \multirow{2}{*}{ Parameter } & \multicolumn{3}{|c|}{$l=1$} & \multicolumn{4}{|c|}{$l=2$} & \multicolumn{2}{|c|}{$l=3$} & \multirow[t]{2}{*}{$b$} \\
\hline & $j=1$ & $j=2$ & $j=3$ & $j=1$ & $j=2$ & $j=3$ & $j=4$ & $j=1$ & $j=2$ & \\
\hline$c$ & 185 & 150 & 210 & 70 & 100 & 80 & 95 & 65 & 55 & - \\
\hline$f$ & 150 & 140 & 196 & 132 & 143 & 94 & 103 & 124 & 78 & 150 \\
\hline$g$ (customer1) & 200 & 180 & 240 & 100 & 115 & 90 & 105 & 85 & 75 & - \\
\hline$g$ (customer2) & 210 & 160 & 250 & 95 & 120 & 95 & 115 & 80 & 80 & - \\
\hline$h$ (customer1) & - & - & - & 95 & 110 & 90 & 100 & 80 & 70 & - \\
\hline$h$ (customer2) & - & - & - & 85 & 120 & 95 & 130 & 80 & 85 & - \\
\hline$e$ (customer1) & & - & & & & & & & & 0.3 \\
\hline$e$ (customer2) & & - & & & & & & & & 0.4 \\
\hline$s($ customer 1$)$ & & 5 & & & & & & & & 2 \\
\hline$s$ (customer2) & & 3 & & & & & & & & 2 \\
\hline
\end{tabular}

Table 2

Results of the example with two secondary categories

\begin{tabular}{|c|c|c|c|c|c|c|c|c|c|c|c|c|}
\hline & \multicolumn{4}{|c|}{ Primary Category } & \multicolumn{3}{|c|}{ direct selling } & \multicolumn{5}{|c|}{ cross-selling } \\
\hline & $j=1$ & $j=2$ & $j=3$ & $j=4$ & $(j, l)=(1,2)$ & $(j, l)=(2,3)$ & $b$ & $(j, l)=(2,3)$ & $(j, l)=(3,1)$ & $(j, l)=(1,2)$ & $b$ & \\
\hline \multicolumn{12}{|c|}{ main model } & \multirow{5}{*}{$\begin{array}{c}\text { Total } \\
\text { Profit }=832\end{array}$} \\
\hline customer 1 & 0 & 1 & 0 & 0 & 1 & 1 & 0 & 0 & in bundle & in bundle & 1 & \\
\hline customer2 & 0 & 0 & 1 & 0 & 1 & 1 & 0 & 1 & in bundle & in bundle & 1 & \\
\hline$z$ & 0 & 1 & 1 & 0 & 1 & 1 & 0 & 1 & in bundle & in bundle & 1 & \\
\hline \multirow[t]{2}{*}{$p$} & - & 180 & 250 & - & 95 & 75 & - & 75 & - & - & 345 & \\
\hline & \multicolumn{4}{|c|}{ Without cross-selling } & & & & & & & & \multirow{5}{*}{$\begin{array}{c}\text { Total } \\
\text { Profit }=180\end{array}$} \\
\hline customer1 & 0 & 1 & 0 & 0 & 1 & 1 & 0 & 0 & 0 & 0 & 0 & \\
\hline customer2 & 0 & 0 & 0 & 0 & 1 & 1 & 0 & 0 & 0 & 0 & 0 & \\
\hline$z$ & 0 & 1 & 0 & 0 & 1 & 1 & 0 & 0 & 0 & 0 & 0 & \\
\hline$p$ & - & 180 & - & - & 95 & 75 & - & - & - & - & - & \\
\hline \multicolumn{12}{|c|}{ Without bundling } & \multirow{5}{*}{$\begin{array}{c}\text { Total } \\
\text { Profit }=334\end{array}$} \\
\hline customer1 & 0 & 0 & 1 & 0 & 1 & 1 & 0 & 0 & 0 & 1 & 0 & \\
\hline customer2 & 0 & 0 & 1 & 0 & 1 & 1 & 0 & 1 & 0 & 0 & 0 & \\
\hline z & 0 & 0 & 1 & 0 & 1 & 1 & 0 & 1 & 0 & 1 & 0 & \\
\hline$p$ & - & - & 240 & - & 95 & 75 & - & 75 & - & 95 & - & \\
\hline
\end{tabular}

As can be seen in Table 2 the optimal assortment for this example is products 2 and 3 from the primary category, product 1 from category 2, product 2 from category 3 and a bundle constituted from product 3 from the primary category and product 1 from category 2 . When cross-selling is overlooked, a suboptimal solution is obtained that result in a significant profit loss of about $78 \%$. In this state the retailer does not benefit from presenting the bundle, because in main model the bundle is purchased by cross-selling and when cross-selling effect is overlooked, no bundle is purchased; also presenting product 3 from primary category is not profitable and this product is eliminated from the assortment and a narrower assortment is yielded. A similar result is obtained when constituting the bundle is not allowed and a pure component (unbundling) strategy is adopted; except that in this state cross-selling 
improves the profit relative to previous state; whereas yet overlooking bundling possibility results in a significant profit loss of about $60 \%$.

This significant profit loss in both states when cross-selling or bundling is overlooked can be observed in larger-scaled instances. The data generation scheme for large size instances are presented in Table 3. As mentioned above, these instances are scaled with respect to the number of categories, the number of candidate products in each category, and the number of customer segments for each category.

Table 3

Data generation scheme

\begin{tabular}{cccccc}
\hline Parameters & $l=1$ & $l=2$ & $l=3$ & $l=4$ & $l=5$ \\
\hline$g_{i j}^{l}$ & Uniform(300,350) & Uniform $(220,270)$ & Uniform $(180,230)$ & Uniform(100,140) & Uniform(40,80) \\
$h_{i j}{ }^{k}$ & - & Uniform $(220,270)$ & Uniform $(180,230)$ & Uniform(100,140) & Uniform(40,80) \\
$c_{j}^{l}$ & Uniform(280,320) & Uniform $(200,240)$ & Uniform $(160,180)$ & Uniform(100,120) & Uniform(30,60) \\
$f_{j}^{l}$ & Uniform(150,170) & Uniform $(120,140)$ & Uniform $(80,100)$ & Uniform(55,70) & Uniform(20,40) \\
\hline
\end{tabular}

Table 4 reports the profit of model for larger instances, as well as for both states that cross-selling and bundling considerations is overlooked. As be shown, the profit losses (as a percentage of the total revenue) that result from overlooking each of two considerations are very significant and change from 26 to 71 percentage for unbundling strategy and from 44 to 83 percentage when cross-selling is not considered. The size of the optimal assortments for all three states is reported and it can be seen that in the model which cross-selling is overlooked the assortment size usually has been decreased. This confirms the results of Ghoniem et al. (2013) that state that overlooking cross-selling effect between retail categories can result in significant profit losses, and suboptimal assortments and prices; although in the present model because of bundling possibility, the condition is more complex. For example in many instances similar to the numerical example that described in details, the customers purchase the bundle by cross-selling effect and ignoring this effect can result in considering an unbundling strategy as optimal strategy that lead to a very significant profit loss. Therefore in order to obtain an optimal solution for assortment selection and pricing decisions for retail categories, an integrated approach that considers cross-selling effect and bundling strategies is required; as has been proposed in this study.

Table 2

Results of model for large instances

\begin{tabular}{|c|c|c|c|c|c|c|c|c|c|c|c|c|c|}
\hline \multicolumn{5}{|c|}{$\begin{array}{l}\text { Number of potential substitutable } \\
\text { products }\end{array}$} & \multicolumn{3}{|c|}{ Maximum profit for: } & \multicolumn{2}{|c|}{ Profit loss $(\%)$} & \multicolumn{3}{|c|}{ The size of optimal assortment } & \multirow{2}{*}{$\begin{array}{l}\text { CPU time } \\
\text { (seconds) }\end{array}$} \\
\hline$l=1$ & $l=2$ & $l=3$ & $l=4$ & $l=5$ & $\begin{array}{l}\text { main } \\
\text { model }\end{array}$ & $\begin{array}{l}\text { Without } \\
\text { bundling }\end{array}$ & $\begin{array}{c}\text { Without } \\
\text { cross } \\
\text { selling }\end{array}$ & $\begin{array}{l}\text { Without } \\
\text { bundling }\end{array}$ & $\begin{array}{c}\text { Without } \\
\text { cross } \\
\text { selling }\end{array}$ & $\begin{array}{l}\text { main } \\
\text { model }\end{array}$ & $\begin{array}{l}\text { Without } \\
\text { bundling }\end{array}$ & $\begin{array}{c}\text { Without } \\
\text { cross } \\
\text { selling }\end{array}$ & \\
\hline \multicolumn{14}{|c|}{ The number of customer segments $=2$} \\
\hline 5 & 7 & 5 & - & - & 806 & 234 & 141 & 71 & 83 & 5 & 3 & 3 & 2.9 \\
\hline 10 & 15 & 10 & - & - & 3891 & 1478 & 1036 & 62 & 73 & 5 & 8 & 5 & 15.5 \\
\hline 25 & 35 & 25 & - & - & 2894 & 1933 & 1478 & 33 & 49 & 6 & 7 & 5 & 462 \\
\hline 15 & 15 & 10 & 10 & - & 2896 & 1593 & 1032 & 45 & 64 & 7 & 4 & 4 & 670 \\
\hline 15 & 15 & 15 & 15 & - & 2655 & 826 & 489 & 69 & 82 & 6 & 6 & 5 & 1000 \\
\hline 5 & 15 & 5 & 15 & 5 & 1851 & 613 & 480 & 67 & 74 & 6 & 6 & 4 & 943 \\
\hline 10 & 10 & 15 & 10 & 10 & 5101 & 3757 & 2858 & 26 & 44 & 9 & 11 & 9 & 982 \\
\hline \multicolumn{14}{|c|}{ The number of customer segments $=3$} \\
\hline 7 & 10 & 7 & - & - & 2716 & 1573 & 1200 & 42 & 56 & 4 & 5 & 3 & 188 \\
\hline 10 & 15 & 10 & - & - & 3928 & 2776 & 1862 & 29 & 53 & 6 & 6 & 4 & 1000 \\
\hline \multicolumn{14}{|c|}{ The number of customer segments $=4$} \\
\hline \multirow[t]{2}{*}{5} & 6 & 5 & - & - & 2368 & 1123 & 918 & 53 & 61 & 5 & 5 & 4 & 993 \\
\hline & & & & Iean : & 2910.6 & 1590.6 & 1149.4 & 50 & 60 & & & & \\
\hline
\end{tabular}


From a computational perspective, it is worthwhile to note that the proposed MIP has solved all instances to optimality, with 3 to 5 product categories and 5 to 35 substitutable products in each category, and 2 or 3 customer segments for each category. For the instances that has been solved in this study, the solution time is less than 17 minutes that indicate the tractability of proposed MIP for even relatively large instances.

\section{Sensitivity analysis}

In this section, some the parameters of the model in the example with two secondary categories that was presented in previous section are changed and the results are analyzed. Table 5 shows the initial and changed values for these parameters as well as the resulted shift in the optimum value of target function.

Table 3

Changed parameters for sensitivity analysis

\begin{tabular}{|c|c|c|c|c|c|c|c|c|c|}
\hline \multirow{2}{*}{ The case } & & \multirow{2}{*}{ Parameter } & \multicolumn{4}{|c|}{$l=2$} & \multicolumn{2}{|c|}{$l=3$} & \multirow{2}{*}{$\begin{array}{c}\text { Objective } \\
\text { function value }\end{array}$} \\
\hline & & & $j=1$ & $j=2$ & $j=3$ & $j=4$ & $j=1$ & $j=2$ & \\
\hline \multirow{4}{*}{ case1 } & \multirow{2}{*}{ Initial values } & $h($ customer 1$)$ & 95 & 110 & 90 & 100 & 80 & 70 & \multirow{2}{*}{832} \\
\hline & & $h$ (customer2) & 85 & 120 & 95 & 130 & 80 & 85 & \\
\hline & \multirow{2}{*}{ changed values } & $h$ (customer 1$)$ & 95 & 110 & 100 & 110 & 90 & 80 & \multirow{2}{*}{862} \\
\hline & & $h$ (customer2) & 90 & 120 & 95 & 130 & 90 & 85 & \\
\hline \multirow{4}{*}{ case 2} & \multirow{2}{*}{ Initial values } & $g$ (customer1) & 100 & 115 & 90 & 105 & 85 & 75 & \multirow{2}{*}{832} \\
\hline & & $g$ (customer2) & 95 & 120 & 95 & 115 & 80 & 80 & \\
\hline & \multirow{2}{*}{ changed values } & $g$ (customer 1$)$ & 100 & 115 & 90 & 105 & 85 & 75 & \multirow{2}{*}{913} \\
\hline & & $g$ (customer2) & 95 & 120 & 95 & 115 & 80 & 90 & \\
\hline \multirow{2}{*}{ case 3} & Initial values & $c$ & 70 & 100 & 80 & 95 & 65 & 55 & 832 \\
\hline & changed values & $c$ & 70 & 100 & 80 & 95 & 65 & 85 & 821 \\
\hline
\end{tabular}

First In case 1 for examining the effect of $h_{i j}{ }^{l}$ values on the amount of cross-selling, the values of $h_{13^{2}}$, $h_{14^{2}}, h_{11^{3}}, h_{12^{2}}{ }^{3} h_{21}{ }^{2}, h_{21}{ }^{3}$ in mentioned example are changed from 90, 100, 80, 70, 85, 80 to 100, 110 , 90, 80, 90, 90; respectively; as this values has been bolded in Table 5. As a result, in optimum solution the value of $y_{12}{ }^{3}$ is 1 and optimum values of other variables remain constant. This is because of increasing $h_{12}{ }^{3}$ from 70 to 80 that result in positive surplus of product 2 from category 3 for customer segment 1 by cross-selling, considering that $p_{2}{ }^{3}$ is equal to 75 . In this case the optimum value of target function is increased from 832 to 862 .

In case 2 , as $g_{22}{ }^{3}$ value is increased from 80 to 90 , customer segment 1 preferred to do not purchase the product 2 from category 3 , because this product results in a negative surplus for this customer segment. In spite of missing customer 1 , increasing optimum value of $p_{2}^{3}$ can improve the value of target function and increase it from 832 to 913 . Also by increasing $c_{2}^{3}$ value from 55 to 85 in case 3 , presenting the product 2 from category 3 because of its negative surplus is not profitable and the product 1 from this category is presented instead of this product. In this case the optimum profit value is decreased from 832 to 821 .

\section{Conclusions and directions for future research}

In this study the problem of assortment selection and pricing multiple retail categories have been examined where bundling decision has been involved. Retailer categories are divided into a primary category and several related secondary categories-each of which is composed of substitutable productsand a cross-selling effect is considered among these categories. First, a mixed-integer nonlinear formulation has developed that maximizes the retailer profit under a maximum utility consumer choice model. Then because of computational considerations, this model has been linearized and converted into a MIP. This reformulation is empirically observed to present exact solutions in manageable times 
(that range from a few CPU seconds to about 16 minutes) even for large-scale, industry-sized instances. The importance of considering possibility of bundling and effect of cross-selling has been demonstrated by presenting a computational study that shows profit losses result from overlooking each of these considerations. In fact, failing to consider each of them, results in suboptimal solutions and significant profit losses. This study can extend by integrating inventory decisions to the model or considering proposed problem in a multi-period horizon. Also, other models (probabilistic or deterministic) can be applied for customer choice, especially for applications that in which the maximum-surplus rule for model isn't adequate.

\section{References}

Adams, W. J., \& Yellen, J. L. (1976). Commodity bundling and the burden of monopoly. The quarterly journal of economics, 475-498.

Arora, R. (2011). Bundling or unbundling frequently purchased products: a mixed method approach. Journal of consumer marketing, 28(1), 67-75.

Azadeh, A., Songhori, M. H., Saberi, M., Hosseini, S., Salarvand, F. and Pazhoheshfar, P. (2014). Deterministic bundle pricing of two products with limited stock. In Intelligent Systems (ICIS), 2014 Iranian Conference, pp. 1-5. IEEE.

Bhunia, A., \& Shaikh, A. (2014). A deterministic inventory model for deteriorating items with selling price dependent demand and three-parameter Weibull distributed deterioration. International Journal of Industrial Engineering Computations, 5(3), 497-510.

Cachon, G. P., \& Kök, A. G. (2007). Category management and coordination in retail assortment planning in the presence of basket shopping consumers. Management Science, 53(6), 934-951.

Cataldo, A., \& Ferrer, J. C. (2016). Optimal pricing and composition of multiple bundles: A two-step approach. European Journal of Operational Research.

Chena, R., \& Jianga, H. (2016). Capacitated Assortment and Price Optimization for Customers with Disjoint Consideration Sets.

Chew, E. P., Lee, L. H. and Wang, Q. (2014). Mixed bundle retailing under a stochastic market. Flexible Services and Manufacturing Journal, 1-24.

Draganska, M., Mazzeo, M., \& Seim, K. (2009). Beyond plain vanilla: Modeling joint product assortment and pricing decisions. Quantitative Marketing and Economics, 7(2), 105-146.

Ghoniem, A., Maddah, B., \& Ibrahim, A. (2013). Optimizing assortment and pricing of multiple retail categories with cross-selling. Journal of Global Optimization, 1-19.

Hall, J. M., Kopalle, P. K., \& Krishna, A. (2010). Retailer dynamic pricing and ordering decisions: category management versus brand-by-brand approaches. Journal of Retailing, 86(2), 172-183.

Jaggi, C., Pareek, S., Khanna, A., \& Sharma, R. (2015). Two-warehouse inventory model for deteriorating items with price-sensitive demand and partially backlogged shortages under inflationary conditions. International Journal of Industrial Engineering Computations, 6(1), 59-80.

Johnson, R. M. (1974). Trade-off analysis of consumer values. Journal of Marketing Research, 11(2), 121-127.

Kraus, U. G., \& Yano, C. A. (2003). Product line selection and pricing under a share-of-surplus choice model. European Journal of Operational Research, 150(3), 653-671.

Katsifou, A., Seifert, R. W., \& Tancrez, J. S. (2014). Joint product assortment, inventory and price optimization to attract loyal and non-loyal customers. Omega, 46, 36-50.

Liao, C. H., \& Tauman, Y. (2002). The role of bundling in price competition. International Journal of Industrial Organization, 20(3), 365-389.

Maddah, B., \& Bish, E. K. (2007). Joint pricing, assortment, and inventory decisions for a retailer's product line. Naval Research Logistics, 54(3), 315-330.

Mayer, S., Klein, R., \& Seiermann, S. (2013). A simulation-based approach to price optimisation of the mixed bundling problem with capacity constraints. International Journal of Production Economics, 145(2), 584-598. 
McElreath, M. H., Mayorga, M. E., \& Kurz, M. E. (2010). Metaheuristics for assortment problems with multiple quality levels. Computers \& Operations Research, 37(10), 1797-1804.

Meyer, J., \& Shankar, V. (2016). Pricing Strategies for Hybrid Bundles: Analytical Model and Insights. Journal of Retailing, 92(2), 133-146.

Moorthy, K. S. (1984). Market segmentation, self-selection, and product line design. Marketing Science, 3(4), 288-307.

Mussa, M., \& Rosen, S. (1978). Monopoly and product quality. Journal of Economic theory, 18(2), 301-317.

Rabbani, M., Zia, N., \& Rafiei, H. (2014). Optimal dynamic pricing and replenishment policies for deteriorating items. International Journal of Industrial Engineering Computations, 5(4), 621-630.

Rodríguez, B., \& Aydın, G. (2011). Assortment selection and pricing for configurable products under demand uncertainty. European Journal of Operational Research, 210(3), 635-646.

Saha, S., \& Basu, M. (2010). Integrated dynamic pricing for seasonal products with price and time dependent demand. Asia-Pacific Journal of Operational Research, 27(03), 393-410.

Surti, C., Hassini, E., \& Abad, P. (2013). Pricing and inventory decisions with uncertain supply and stochastic demand. Asia-Pacific Journal of Operational Research, 30(06), 1350030.

Talebian, M., Boland, N., \& Savelsbergh, M. (2014). Pricing to accelerate demand learning in dynamic assortment planning for perishable products. European Journal of Operational Research, 237(2), 555-565.

Venkatesh, R., \& Kamakura, W. (2003). Optimal bundling and pricing under a monopoly: Contrasting complements and substitutes from independently valued products*. The Journal of business, 76(2), 211-231.

Walters, R. G. (1991). Assessing the impact of retail price promotions on product substitution, complementary purchase, and interstore sales displacement. The Journal of Marketing, 17-28.

Zhang, J. L. (2012). Integrated decision on pricing, promotion and inventory management. Asia-Pacific Journal of Operational Research, 29(06), 1250038.

Zhang, Y. (2015). Designing a retail store network with strategic pricing in a competitive environment. International Journal of Production Economics, 159, 265-273.

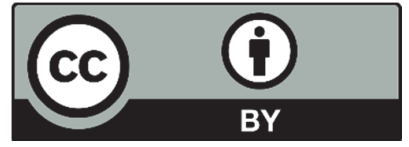

(C) 2017 by the authors; licensee Growing Science, Canada. This is an open access article distributed under the terms and conditions of the Creative Commons Attribution (CC-BY) license (http://creativecommons.org/licenses/by/4.0/). 